\title{
Intracortical Circuits in Thalamorecipient Layers of Auditory Cortex Refine after Visual Deprivation
}

\author{
Xiangying Meng, ${ }^{1}$ Joseph P. Y. Kao, ${ }^{2}{ }^{\circ}$ Hey-Kyoung Lee, ${ }^{1,3}$ and ${ }^{\circledR P a t r i c k}$ O. Kanold ${ }^{1}$
}

DOI:http://dx.doi.org/10.1523/ENEURO.0092-17.2017

${ }^{1}$ Department of Biology, University of Maryland, College Park, MD 20742, ${ }^{2}$ Center for Biomedical Engineering and Technology, and Department of Physiology, University of Maryland School of Medicine, Baltimore, MD 21201, and

${ }^{3}$ Department of Neuroscience, Mind/Brain Institute, Johns Hopkins University, Baltimore, MD 21218

\section{Visual Abstract}

Normal Reared

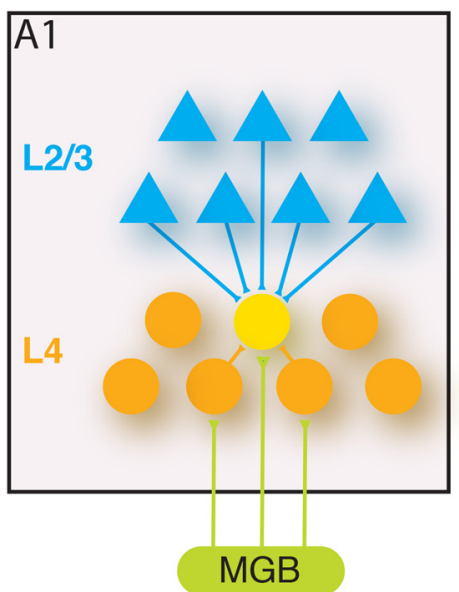

Dark Exposed

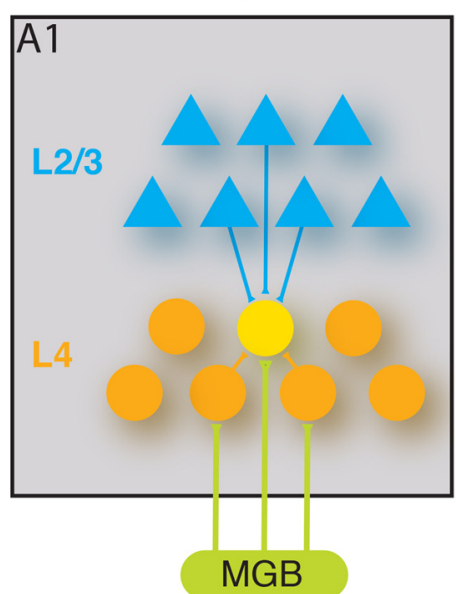

Sensory cortices do not work in isolation. The functional responses of neurons in primary sensory cortices can be affected by activity from other modalities. For example, short-term visual deprivations, or dark exposure (DE), leads to enhanced neuronal responses and frequency selectivity to sounds in layer 4 (L4) of primary auditory cortex (A1). Circuit changes within A1 likely underlie these changes. Prior studies revealed that $D E$ enhanced thalamocortical transmission to L4 in A1. Because the frequency selectivity of L4 neurons is determined by both thalamocortical and intracortical inputs, changes in intralaminar circuits to L4 neurons might also contribute to improved sound responses. We thus investigated in mouse A1 whether intracortical circuits to L4 cells changed after DE. Using in vitro whole-cell patch recordings in thalamocortical slices from mouse auditory cortex, we show that DE can lead to refinement of interlaminar excitatory as well as inhibitory connections from L2/3 to L4 cells, manifested as a weakening of these connections. The circuit refinement is present along the tonotopic axis, indicating reduced integration along the tonotopic axis. Thus, cross-modal influences may alter the spectral and temporal processing of sensory stimuli in multiple cortical layers by refinement of thalamocortical and intracortical circuits.

Key words: Auditory cortex; intracortical; dark exposure; visual deprivation; crossmodal; mouse; refinement;

\section{Significance Statement}

Temporary visual deprivation leads to sharper frequency selectivity and increased sensitivity of thalamorecipient neurons in layer 4 (L4) of primary auditory cortex (A1). Although thalamocortical synapses in A1 are strengthened after visual deprivation, the intracortical circuit changes underlying the functional changes in L4 are poorly understood. We here investigated the functional microcircuits targeting $L 4$ neurons. We show that visual deprivations cause a spatial refinement of interlaminar excitatory and inhibitory connections from $L 2 / 3$ to $L 4$ cells but not within $L 4$. The circuit refinement is present along the tonotopic axis, indicating reduced integration along the tonotopic axis. Our findings show that cross-modal influences can impact the processing of sensory stimuli in L4 by adjusting both thalamocortical and intracortical circuits. 
plasticity; layer 4

\section{Introduction}

Our perception of the world relies on the integration of inputs from multiple senses, with sensory inputs from different modalities being integrated at different stages of processing. The interaction of the different modalities can be uncovered during the loss of a sensory modality, which often leads to enhanced function of one or more of the remaining senses in a process often termed "cross-modal plasticity" (Bavelier and Neville, 2002; Lee and Whitt, 2015). The best-studied group of individuals are the early or late blind, who can show enhanced performance in the remaining senses, for example better sound localization (Lessard et al., 1998; Röder et al., 1999) and pitch discrimination (Gougoux et al., 2004), than sighted individuals. These behavioral results suggest that the absence of vision may trigger changes in circuits underlying auditory perception. There is accumulating evidence that even primary sensory cortices receive information from other sensory systems. These inputs mainly activate the superficial layers of a primary sensory cortex (Lakatos et al., 2007; lurilli et al., 2012; Ibrahim et al., 2016), are thought to be important for multisensory integration under normal conditions (Schroeder and Foxe, 2005; Ghazanfar and Schroeder, 2006), and have the ability to trigger profound circuit plasticity. Because thalamorecipient layer 4 (L4) cells receive input from the superficial layers (Barbour and Callaway, 2008; Kratz and Manis, 2015), multisensory inputs might thus sculpt circuits in thalamorecipient layers. Indeed, after the critical period, depriving mice of vision by dark exposure (DE) for $\sim 1$ week alters the sound-evoked responses in layer 4 (L4) of primary auditory cortex (A1; Petrus et al., 2014). L4 cells responded more robustly to sounds, consistent with increased thalamocortical transmission after DE (Petrus et al., 2014). L4 neurons also showed increased frequency selectivity (Petrus et al., 2014). Because frequency selectivity tuning of A1 neurons depends on intracortical circuits ( $\mathrm{Li}$ et al., 2013 , 2014), increased selectivity suggests that intracortical circuits to $L 4$ neurons were altered after DE. Because in vitro studies showed that a period of DE can refine ascending and intralaminar excitatory and inhibitory circuits to L2/3 neurons (Meng et al., 2015), we speculated that $D E$ could also alter intracortical circuits to L4 neurons

Received March 20, 2017; accepted March 24, 2017; First published April 3, 2017.

Authors report no conflict of interest.

HKL and POK designed research. XM performed LSPS experiments and analyzed the data. POK supervised research. JPYK contributed reagents. $\mathrm{XM}, \mathrm{HKL}$, JPYK, and POK discussed the results and wrote the manuscript.

Supported by NIH R01EY022720 (HKL and POK) and NIH R01 GM056481 (JPYK).

Correspondence should be addressed to Patrick O. Kanold, Department of Biology, University of Maryland, 1116 Biosciences Res. Bldg., College Park, MD 20742. E-mail: pkanold@umd.edu.

DOI:http://dx.doi.org/10.1523/ENEURO.0092-17.2017

Copyright (C) 2017 Meng et al.

This is an open-access article distributed under the terms of the Creative Commons Attribution 4.0 International license, which permits unrestricted use, distribution and reproduction in any medium provided that the original work is properly attributed. and that such circuit changes could contribute to the increased frequency selectivity.

L4 cells in A1 receive inputs from within L4, and these inputs can be patchy (Barbour and Callaway, 2008; Zhao et al., 2009; Kratz and Manis, 2015), similar to intralaminar inputs to L2/3 cells (Watkins et al., 2014). Additional inputs to $\mathrm{L} 4$ cells originate in L2/3 as well as weak projection from L5/6 (Barbour and Callaway, 2008; Zhao et al., 2009). In particular, because in vitro recordings from $L 4$ had shown that intralaminar connections to L4 neurons are strengthened (Petrus et al., 2015), we speculated that interlaminar connections to L4 neurons might change in the opposite manner.

To identify which microcircuits in L4 A1 neurons are affected by visual experience, we use laser-scanning photostimulation (LSPS) to map spatially the connectivity of excitatory and inhibitory inputs to L4 neurons to determine whether visual deprivation alters their circuit topology. We find that 6-8 d of dark rearing alters the spatial pattern of both excitatory and inhibitory interlaminar connections originating in L2/3. Excitatory and inhibitory inputs originating from L2/3 were confined to a smaller area along the rostro-caudal tonotopic axis, indicating refinement of lateral connections consistent with increased spectral selectivity. Moreover, inputs from L2/3 were weaker, indicating an increase in feed-forward processing of L4. Together, our results show that DE can refine the intracortical circuits in multiple layers of $A 1$ to facilitate enhanced spectro-temporal processing of sound stimuli.

\section{Methods}

\section{Animals}

All procedures followed the University of Maryland College Park animal use regulations. Male and female C57BL/6J mice (Jackson Laboratory) were raised in 12-h light/12-h dark conditions. At postnatal day 21 (P21)-P22, mice (two to three mice from established litters and single gender per cage) were dark exposed (DE) for 6-8 d. Age-matched controls remained in normal light conditions (NR).

\section{Slice preparation}

Mice are deeply anesthetized with isoflurane (Halocarbon). A block of brain containing $\mathrm{A} 1$ and the medial geniculate nucleus (MGN) is removed, and thalamocortical slices (500 $\mu \mathrm{m}$ thick) are cut on a vibrating microtome (Leica) in ice-cold ACSF containing (in mM) $130 \mathrm{NaCl}, 3$ $\mathrm{KCl}, 1.25 \mathrm{KH}_{2} \mathrm{PO}_{4}, 20 \mathrm{NaHCO}_{3}, 10$ glucose, $1.3 \mathrm{MgSO}_{4}$, and $2.5 \mathrm{CaCl}_{2}\left(\mathrm{pH} 7.35-7.4\right.$, in $\left.95 \% \mathrm{O}_{2} / 5 \% \mathrm{CO}_{2}\right)$. For $\mathrm{A} 1$ slices, the cutting angle is $\sim 15$ degrees from the horizontal plane (lateral raised; Cruikshank et al., 2002; Zhao et al., 2009; Meng et al., 2015). Slices are incubated for 1 $\mathrm{h}$ in ACSF at $30^{\circ} \mathrm{C}$ and then kept at room temperature. For recording, slices are held in a chamber on a fixed-stage microscope (Olympus BX51) and superfused (2-4 ml/min) with high-Mg ACSF recording solution at room temperature to reduce spontaneous activity in the slice. The recording solution contained (in mM) $124 \mathrm{NaCl}, 5 \mathrm{KCl}, 1.23$ 
$\mathrm{NaH}_{2} \mathrm{PO}_{4}, 26 \mathrm{NaHCO}_{3}, 10$ glucose, $4 \mathrm{MgCl}_{2}$, and $4 \mathrm{CaCl}_{2}$. The location of the recording site in $\mathrm{A} 1$ was identified by landmarks (Cruikshank et al., 2002; Zhao et al., 2009; Meng et al., 2015).

\section{Electrophysiology}

Whole-cell recordings are performed with a patch clamp amplifier (Multiclamp 700B, Molecular Devices) using pipettes with input resistance of 4-9 $\mathrm{M} \Omega$. Cells targeted for recording are located in an area of $A 1$ overlying the rostral flexure of the hippocampus. Data acquisition is performed by National Instruments AD boards and custom software (Ephus; Suter et al., 2010), which is written in Matlab (Mathworks) and adapted to our setup. Voltages are corrected for an estimated junction potential of $10 \mathrm{mV}$. Electrodes are filled with (in $\mathrm{mM}$ ) 115 cesium methanesulfonate $\left(\mathrm{CsCH}_{3} \mathrm{SO}_{3}\right), 5 \mathrm{NaF}, 10 \mathrm{EGTA}, 10 \mathrm{HEPES}, 15 \mathrm{CsCl}$, 3.5 MgATP, and 3 QX-314 (pH 7.25, 300 mOsm). Biocytin or neurobiotin $(0.5 \%)$ is added to the electrode solution as needed. Series resistances were typically $20-25 \mathrm{M} \Omega$. For photostimulation, $0.5-1 \mathrm{~mm}$ caged glutamate [ $\mathrm{N}$-(6-nitro7-coumarinylmethyl)-L-glutamate; Ncm-Glu; Kao, 2006; Muralidharan et al., 2016] is added to the ACSF. Without UV light, this compound has no effect on neuronal activity (Kao, 2006; Muralidharan et al., 2016). UV laser light (500 $\mathrm{mW}, 355 \mathrm{~nm}, 1-\mathrm{ms}$ pulses, $100-\mathrm{kHz}$ repetition rate, DPSS) is split by a $33 \%$ beam splitter (CVI Melles Griot), attenuated by a Pockels cell (Conoptics), gated with a laser shutter (NM Laser), and coupled into a microscope via scan mirrors (Cambridge Technology) and a dichroic mirror. The laser beam in LSPS enters the slice axially through the objective (Olympus 10×, $0.3 \mathrm{NA}$ /water) and has a diameter of $<20 \mu \mathrm{m}$. Laser power at the sample is $<25 \mathrm{~mW}$. We typically stimulate up to $40 \times 35$ sites spaced $30 \mu \mathrm{m}$ apart, enabling us to probe areas of $1 \mathrm{~mm}^{2}$; such dense sampling reduces the influence of potential spontaneous events. Repeated stimulation yielded essentially identical maps. Stimuli are applied at $0.5-1 \mathrm{~Hz}$. Analysis was performed essentially as described previously with custom software written in Matlab (Meng et al., $2014,2015)$. Activation profiles of neurons were produced by recording in cell-attached mode while mapping the same region and recording action potentials. To detect monosynaptically evoked postsynaptic currents (PSCs), we detected PSCs with onsets in an $\sim 50-\mathrm{ms}$ window after the stimulation (Fig. 1C). This window was chosen based on the observed spiking latency under our recording conditions (Meng et al., 2015). Our recordings are performed at room temperature and in high- $\mathrm{Mg}^{2+}$ solution to reduce the probability of polysynaptic inputs. We measured both peak amplitude and transferred charge; transferred charge was measured by integrating the PSC. Although the transferred charge might include contributions from multiple events, our prior studies showed a strong correlation between these measures (Viswanathan et al., 2012; Meng et al., 2014, 2015). Traces containing a short-latency $(<8 \mathrm{~ms})$ "direct" response were discarded from the analysis (Fig. 1E, black patches in color-coded maps), as were traces that contained longer-latency inward currents of long duration (>50 ms). These currents could sometimes be seen in locations surrounding $(<100$ $\mu \mathrm{m})$ areas that gave a direct response. Occasionally, some of the direct responses contained synaptic evoked responses that we did not separate out, leading to an underestimation of local short-range connections. Cells that did not show any large $(>100 \mathrm{pA})$ direct responses were excluded from the analysis, as these could be astrocytes. It is likely that the observed PSCs at each stimulus location represent the activity of multiple presynaptic cells. Layer boundaries were determined from the infrared pictures.

\section{Statistics}

Results are plotted as means \pm SD unless otherwise indicated. Populations are compared with a rank sum or Student's $t$ test (based on Lilliefors test for normality), and the PSTH variance comparison is done with $F$ test and deemed significant if $p<0.05$.

\section{Results}

We use laser-scanning photostimulation (LSPS) with caged glutamate (Shepherd et al., 2003; Meng et al., $2014,2015)$ to map spatially the connectivity of excitatory and inhibitory inputs to $A 1$ neurons to determine whether temporary visual deprivation alters circuits in $\mathrm{A} 1$ (Fig. $1 A$ ). We thus compare mice raised in normal light conditions (NR) with mice that were dark exposed (DE) from $1 \mathrm{wk}$ starting at $\sim P 21$ and mapped cells from NR and DE animals at P28-P30. Cells from NR and DE were located at similar laminar positions (Fig. $1 B ; p=0.3$ ). We previously showed by cell-attached recordings that DE does not cause increased excitability or increased sensitivity of $L 4$ and $L 2 / 3$ cells to glutamate (e.g., by redistribution of GluRs to the soma or proximal dendrites; Meng et al., 2015).

\section{Interlaminar excitatory connections to A1 L4 neurons change after DE}

We first investigated whether the spatial pattern of intra- and interlaminar connectivity to L4 neurons is altered after DE. To visualize the spatial pattern of excitatory inputs of each cell, we performed whole-cell patch recordings and targeted the laser pulse to multiple distinct stimulus locations and record the resulting membrane currents (Fig. 1A). If the neuron activated by the laser pulse was connected to the recorded neuron, then evoked PSCs were observed. By holding cells at a membrane potential of $-70 \mathrm{mV}\left(\sim E_{\mathrm{Cl}}\right)$ we can isolate EPSCs (Fig. $1 A, C$ ). We then targeted the laser pulse to multiple distinct stimulus locations and recorded the resulting membrane currents. The targeted stimulus locations spanned the entire extent of $A 1$, thus enabling us to probe the entire 2D connection pattern of excitatory inputs to a given cell over $\sim 1 \mathrm{~mm}^{2}$ (Fig. 1A). Because activation of the cell body and proximal dendrites causes a largeamplitude short-latency direct event and synaptic currents have a distinct latency ( $>8 \mathrm{~ms})$, we can separate them by latency criteria (Fig. $1 C$ ).

We mapped L4 cells ( $n=46$ cells) in A1 and examined the connection pattern of excitatory inputs. L4 cells in normal reared animals (NR, $n=27$ cells) received excitatory input from within L4 as well as from L2/3 and L5/6 
A

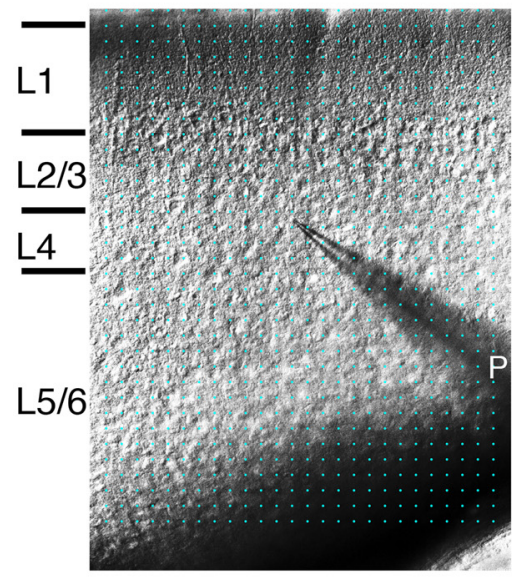

B

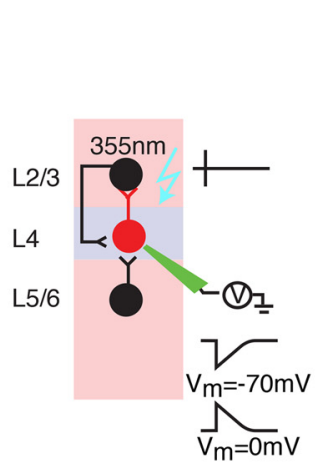

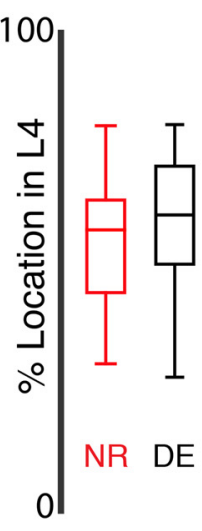

C

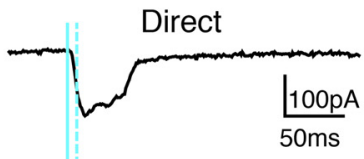

D $\quad V_{m}=-70 m V$

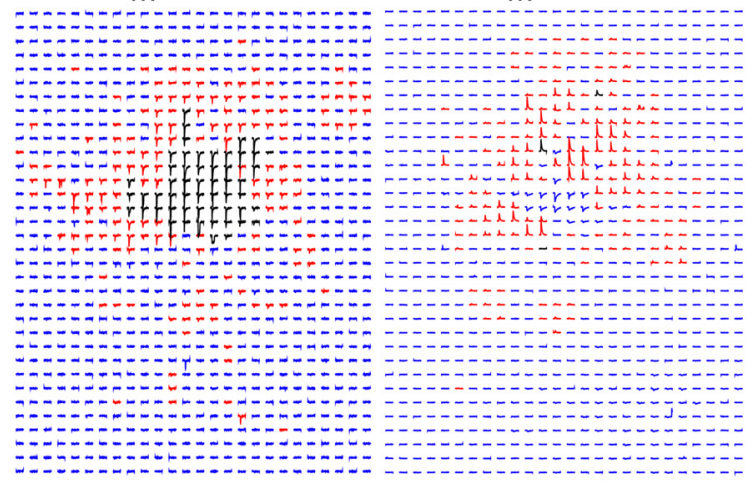

E EPSC charge

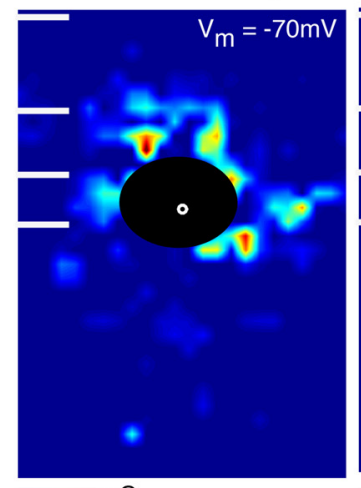

${ }_{0} \mathrm{pc}$
IPSC charge

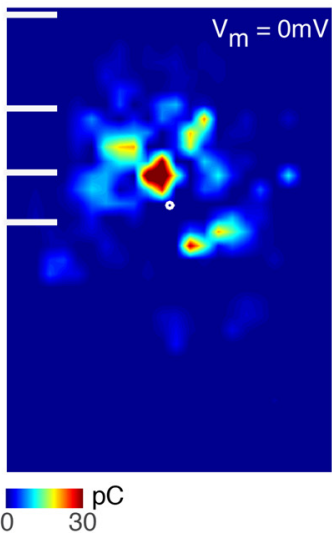

Figure 1. LSPS to map intracortical connections to L4 cells. $\boldsymbol{A}$, Left, infrared image of brain slice with patch pipette on L4 neuron. Stimulation grid is indicated by blue dots. Right, schematic of LSPS experiment. Whole-cell patch-clamp recordings are made from L4 neurons. Cells are held at -70 and $0 \mathrm{mV}$. Laser pulses $(355 \mathrm{~nm})$ are targeted to an array of locations in the slice. Traces on right, activated cells fire action potentials (top), and if a connection exists to the patched L4 neuron, evoked EPSCs and IPSCs are recorded (bottom). B. The relative position of patched cells within L4. 0 refers to the border with L5 and 100 refers to the border with L3. Cells were sampled from the middle of layer 4 in NR and DE animals $\left(p=3.05 \times 10^{-1}\right)$. $\boldsymbol{C}$, Whole-cell voltage clamp recordings at holding potentials of $-70 \mathrm{mV}$ (top) or $0 \mathrm{mV}$ (bottom) distinguish between photostimulation-evoked excitatory and inhibitory currents. Shown are traces obtained with photostimulation at different locations. Solid blue line indicates time of photostimulation; dashed blue line marks 8-ms poststimulus, which is the minimal latency for synaptic responses. $\boldsymbol{D}$. Traces obtained by LSPS when holding one L4 neuron at -70 and $0 \mathrm{mV}$, respectively. Traces showing large-amplitude direct responses are shown in black. The responses that have latencies between 8 and 50 ms are shown in red. Otherwise, the traces are shown in blue. E, Pseudocolor maps show PSC charge at each stimulus location for the example cell in $\boldsymbol{D}$. Direct responses indicated were set to zero (overlaid by black area). White filled circle marks the soma location. Horizontal bars indicate layer borders.

(Fig. 1D, E), consistent with prior studies (Barbour and Callaway, 2008; Zhao et al., 2009; Kratz and Manis, 2015). To analyze connectivity pattern changes over the population of cells, individual LSPS maps were aligned to the cell body position and averaged; the result is a spatial map of connection probability (Fig. $2 A, B$ ). These maps showed that L4 cells were connected to other L4 cells up to $500 \mu \mathrm{m}$ apart. Because our thalamocortical slices contain the tonotopic axis, this indicates that L4 cells can integrate inputs that are more than one octave above or below the cell's best frequency (BF).

Altered synaptic connectivity can be manifested as altered occurrence of connections as well as changes in the strength of existing connections. We therefore analyzed the spatial connection probability and the spatial connection strength separately. When qualitatively comparing $N R$ to $D E$, we find that after DE there are distinct differences in excitatory inputs to L4 neurons (Fig. 2B, NR: $n=$ 27; DE: $n=19$ ). Overall there seems to be a reduction in connection probability for inputs originating from $L 2 / 3$ and L4. Although average connection maps allow a coarse assessment of changes, detailed changes in connection profiles cannot be extracted when the individual connection profiles are diverse (Meng et al., 2015). Therefore, we analyzed properties of the connection patterns for each individual cell in detail and compared these properties 
A

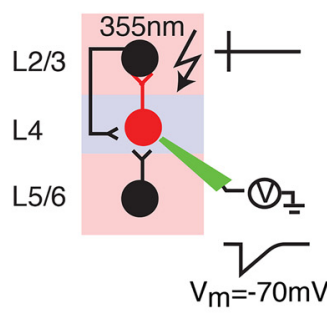

B EPSC P(connection)

NR

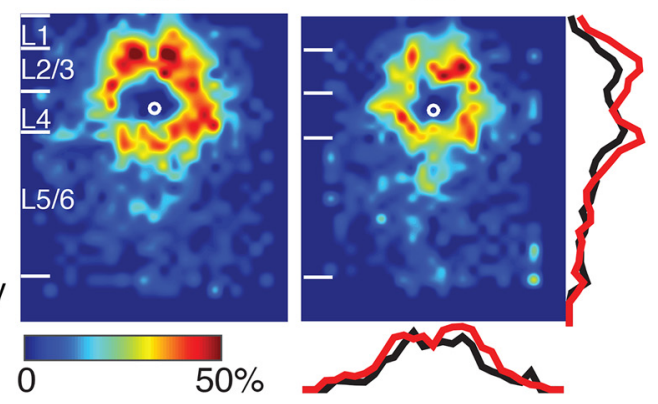

C

Total area
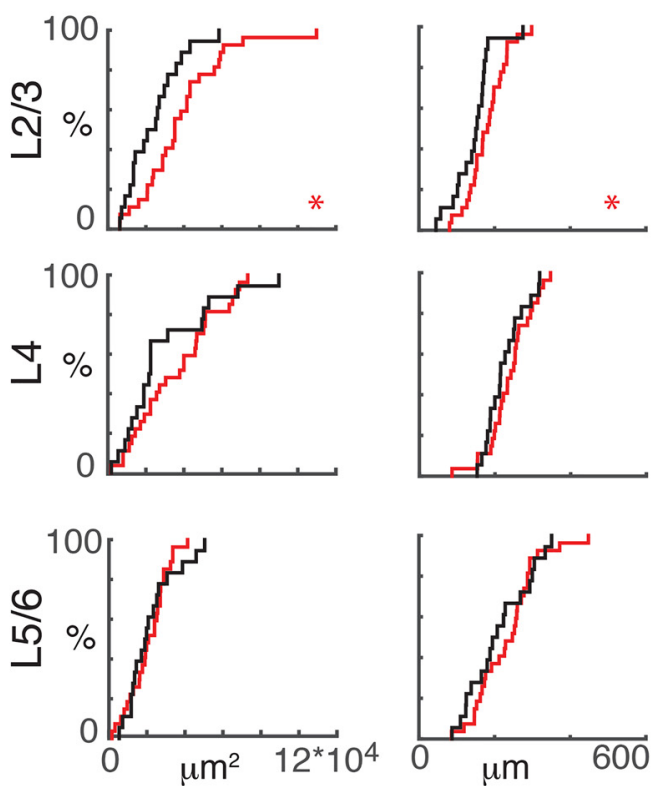

Distance

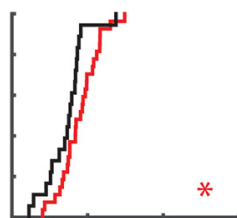

Figure 2. Interlaminar cortical excitatory connections to L4 cells refine with DE. $\boldsymbol{A}$, Schematic of LSPS experiment. Whole-cell patch-clamp recordings are made from L4 neurons. Cells are held at $-70 \mathrm{mV}$. Laser pulses (355 nm) are targeted to an array of locations in the slice. Traces on right, activated cells fire action potentials (top), and if a connection exists to the patched L4 neuron, evoked EPSCs are recorded (bottom). B, Average maps (aligned to soma, white circle) of connection probability for excitatory connections in NR (left) and DE (right) animals. Connection probability is encoded according to the pseudocolor scale. White horizontal lines indicate averaged laminar borders and are $100 \mu \mathrm{m}$ long. Traces at the right of the DE panel the laminar marginal distributions (red for NR and black for DE). Traces at the bottom of the DE panel are the columnar marginal distributions. Note that NR and DE maps and distributions appear different. C, Distributions of area of input originating from L2/3 (top), L4 (middle), and L5/6 (bottom) of NR (red) or DE (black) animals. $*, p<0.05$. The $p$ values for the total area from L2/3, L4, and L5/6 are 0.02 (NR: mean $=3.8$ $\times 10^{4} \mu \mathrm{m}^{2}$, std $=2.2 \times 10^{4} \mu \mathrm{m}^{2}$; DE: mean $=2.4 \times 10^{4} \mu \mathrm{m}^{2}$, std $\left.=1.4 \times 10^{4} \mu \mathrm{m}^{2}\right), 0.74\left(\mathrm{NR}:\right.$ mean $=2.1 \times 10^{4} \mu \mathrm{m}^{2}$, std $=1.0 \times 10^{4}$ $\mu \mathrm{m}^{2}$; DE: mean $=2.2 \times 10^{4} \mu \mathrm{m}^{2}$, std $\left.=1.3 \times 10^{4} \mu \mathrm{m}^{2}\right)$, and $0.32\left(\mathrm{NR}\right.$ : mean $=3.6 \times 10^{4} \mu \mathrm{m}^{2}$, std $=2.1 \times 10^{4} \mu \mathrm{m}^{2} ; \mathrm{DE}: \mathrm{mean}^{2}=$ $2.9 \times 10^{4} \mu \mathrm{m}^{2}$, std $\left.=2.4 \times 10^{4} \mu \mathrm{m}^{2}\right)$, respectively. $\boldsymbol{D}$, Distributions of the distance of $80 \%$ of input to each L4 cell originating from L2/3 (top), L4 (middle), and L5/6 (bottom) of NR (red) or DE (black) animals. We calculated the laminar radius that covers $80 \%$ of inputs inside each layer and plotted the CDFs of the radius. $*, p<0.05$. All comparisons were done with Wilcoxon rank-sum test or Student's $t$ test. The $p$ values for the average $80 \%$ distance from L2/3, L4, and L5/6 are 0.028 (NR: mean $=179.2 \mu \mathrm{m}$, std $=51 \mu \mathrm{m}$; DE: mean $=143.6 \mu \mathrm{m}$, std $=52.3 \mu \mathrm{m}), 0.40(\mathrm{NR}:$ mean $=239.4 \mu \mathrm{m}$, std $=58.7 \mu \mathrm{m} ; \mathrm{DE}:$ mean $=225.2 \mu \mathrm{m}$, std $=49.9 \mu \mathrm{m})$, and $0.39(\mathrm{NR}$ : mean $=233.5 \mu \mathrm{m}$, std $=79.8 \mu \mathrm{m} ; \mathrm{DE}:$ mean $=212.2 \mu \mathrm{m}$, std $=81.0 \mu \mathrm{m})$, respectively.

over the population. To quantify the laminar changes, we identified laminar borders for each cell from the differential interference contrast (DIC) images and calculated the input profile from each layer. To visualize and quantify the differences between cells, we determined the total area in each layer where stimulation evoked EPSCs in L4 neu- rons. We found that after $D E$, the area of excitatory inputs originating from $L 2 / 3$ but not $L 4$ was decreased, suggesting a pruning/refinement of functional interlaminar but not intralaminar connections (Fig. 2C). To further analyze the functional connectivity, we calculated the laminar distance from each functionally connected stimulation site to 
the recorded cells. After $D E$, inputs from $L 2 / 3$ originated from closer distances than in NR (Fig. 2D), consistent with pruning or refinement of interlaminar inputs.

\section{Interlaminar inhibitory connections to A1 L4 neurons change after DE}

Our results show a remodeling of excitatory connections. We next investigated whether inhibitory connections also change after DE. We mapped inhibitory connections by holding cells at $0 \mathrm{mV}\left(\sim E_{\text {glut }}\right.$; Figs. $1 D, E$, and $3 A$ ). Average maps of connection probability and connection strength appeared different after $\mathrm{DE}$, in that the cortical area giving rise to inhibitory responses decreased (Fig. 3B). This was confirmed quantitatively: the total area generating inhibitory input in L2/3 was reduced after DE compared with NR controls (Fig. 3C). However, in contrast to the excitatory inputs, analysis of the distance from where inputs could be evoked did not show differences after DE (Fig. 3D). This indicates that the refinement of inhibitory inputs is due to refinement within L2/3 with inhibitory inputs originating from a smaller sublamina within L2/3 after DE. Taken together, the above results demonstrate refinement of both excitatory and inhibitory connections originating in L2/3 after DE while inputs from L4 and L5/6 did not change.

\section{The strength of interlaminar connections to A1 L4 neurons changes after DE}

Circuit changes can involve changes in connection probability as well as changes in synaptic strength. Therefore, we next investigated whether the strength of events evoked from each layer changed after DE. Because synaptic events can change in amplitude as well as duration, we calculated both charge and peak amplitude of the evoked EPSCs. We found that the mean EPSC charge, as well as EPSC amplitude of events originating from L2/3 and $L 5 / 6$, decreased after DE (Figs. $4 A, B$ and $5 A, B$ ). Because the amplitude of events originating in L4 did not change, the fractional charge $L 4$ cells received from within L4 as opposed to interlaminar inputs increased (Figs. $4 C$ and $5 C$ ). The laminar changes in IPSC strength after DE mirrored the changes in EPSC strength. The average charge and amplitude of uncaging evoked IPSC was decreased in L2/3 after DE (Figs. $4 D, E$ and $5 D, E$ ), leading to a relative increase in input from L4 (Figs. $4 F$ and $5 F$ ). Together, these results demonstrate a weakening of interlaminar excitatory and inhibitory inputs from L2/3 to L4 neurons after DE.

\section{The balance of excitation and inhibition from L2/3 to L4 changes after DE}

DE results in a balanced refinement of excitatory and inhibitory connections to L2/3 neurons (Meng et al., 2015). Because thalamic input to $L 4$ neurons is increased after DE (Petrus et al., 2014), the adjustment of intracortical circuits to L4 neurons might compensate for this additional driving input. We thus investigated whether the changes in the spatial pattern of excitatory and inhibitory connection to L4 neurons occur in a balanced manner. We computed the excitation/inhibition (EI) ratio based on input area, transferred charge, and peak amplitude for every cell. Because we could not assess excitatory input in locations that gave direct responses for excitation, we excluded those stimulus locations in our calculations for both excitation and inhibition. Our calculations showed that the El ratio for L2/3 inputs decreased after DE (Fig. 6), indicating that L4 neurons received less excitatory input from L2/3. This suggests that increased firing rates in response to sound stimulation after DE are due to increased thalamocortical input (Petrus et al., 2014).

\section{Discussion}

We here show that short-term DE causes a refinement of the functional intracortical circuitry to layer 4 neurons of A1. We found that interlaminar excitatory inputs from L2/3 and $L 5 / 6$ originate from smaller areas along the rostrocaudal tonotopic axis, indicating a refinement of these connections. DE not only changed excitatory inputs to $L 4$ neurons. Inhibitory connections from $L 2 / 3$, as well as from L5/6, also originated from reduced areas. Thus, overall, there is a net decrease in the spatial extent of both interlaminar excitation and inhibition to L4 cells. In contrast, intralaminar inputs from within L4 did not change after DE. Because the frequency selectivity of $A 1$ neurons depends on intracortical circuits (Li et al., 2013, 2014), the circuit refinement along the tonotopic axis is consistent with the increasing frequency selectivity of L4 neurons in vivo (Petrus et al., 2014). Moreover, our results suggest that interlaminar inputs from L2/3 may help shape the frequency selectivity of $L 4$ neurons. Although we detect refinement of $L 2 / 3$ to $L 4$ connections, intralaminar connections within L4 were not changed. Neighboring L4 neurons show higher similarity in their frequency selectivity than L2/3 neurons (Bandyopadhyay et al., 2010, Winkowski and Kanold, 2013, and Kanold et al., 2014), suggesting that the refinement we observe in L2/3 decreases connections between neurons of different frequency selectivity. Together with the strengthening of thalamocortical connections to L4 neurons after DE (Petrus et al., 2014), this indicates that DE causes a remodeling of all inputs to L4 neurons in A1 to improve sound processing. Finally, because DE also causes remodeling of $A 1$ circuits in $L 2 / 3$, our results suggest that A1 processing in general can be highly plastic after the critical period (Meng et al., 2015).

We analyzed A1 circuits using LSPS, which reveals the connections between the photostimulated neurons and the neuron being monitored by patch clamp. Because presynaptic neurons can connect to postsynaptic neurons via multiple individual synapses, the reduction in connection strength from $L 2 / 3$ to $L 4$ we observed could have been due to fewer synapses between L2/3 and L4 neurons or the weakening of synapses. Analysis of individual synaptic inputs to L4 neurons showed that DE increased synaptic amplitude of intralaminar connections within L4 (Petrus et al., 2015). We did not detect a change in LSPS-evoked amplitude, suggesting that L4 neurons are connected to each other with fewer but stronger synapses. Moreover, the spatial resolution of our LSPS technique is $\sim 100 \mu \mathrm{m}$ owing to the direct response. As a result, we cannot measure 
A

B IPSC P(connection)

NR $\quad$ DE
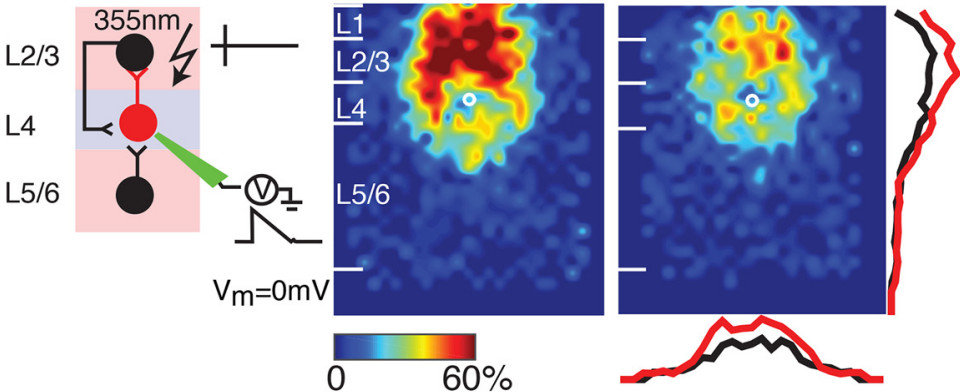

$060 \%$

C

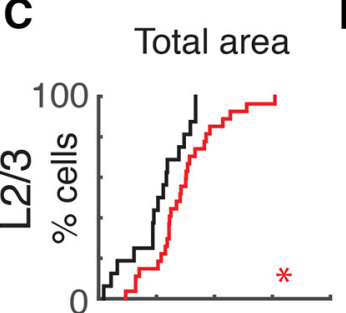

D Distance
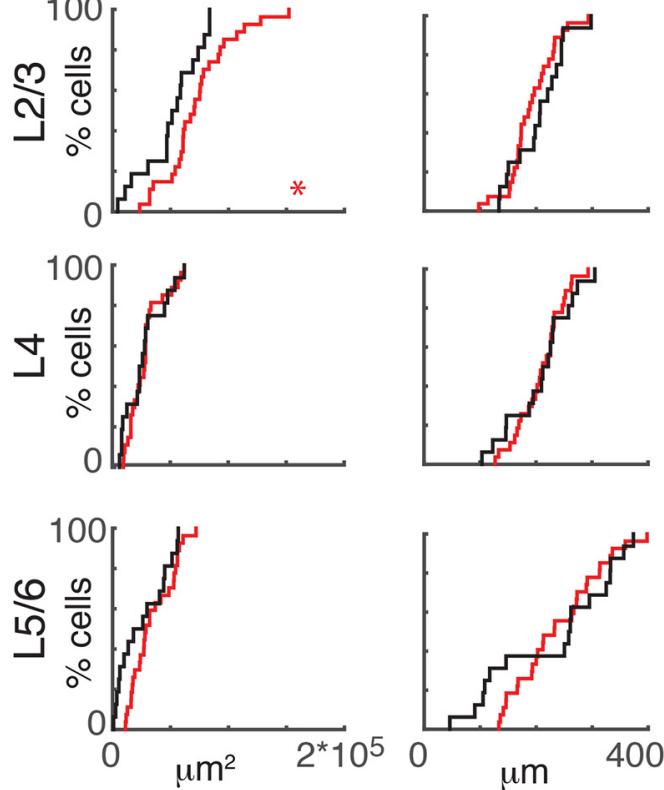

Figure 3. Interlaminar cortical inhibitory connections to L4 cells refine. $\boldsymbol{A}$, Schematic of LSPS experiment. Whole-cell patchclamp recordings are made from L4 neurons. Cells are held at $0 \mathrm{mV}$. Laser pulses $(355 \mathrm{~nm})$ are targeted to an array of locations in the slice. Traces on right, activated cells fire action potentials (top), and if a connection exists to the patched L4 neuron, evoked IPSCs are recorded (bottom). B. Average maps (aligned to soma, white circle) of connection probability for inhibitory connections in NR (left) and DE (right) animals. Connection probability is encoded according to the pseudocolor scale. White horizontal lines indicate averaged laminar borders and are $100 \mu \mathrm{m}$ long. Traces at the right of the DE panel are the laminar marginal distributions (red for NR and black for DE). Traces at the bottom of the DE panel are the columnar marginal distributions. Note that NR and DE maps and distributions appear different. $\mathbf{C}$, Distributions of area of input originating from L2/3 (top), L4 (middle), and L5/6 (bottom) of NR (red) or DE (black) animals. *, $p<0.05$. The $p$ values for the total area from L2/3, L4, and L5/6 are 0.02 (NR: mean $=7.3 \times 10^{4} \mu \mathrm{m}^{2}$, std $=2.9 \times 10^{4} \mu \mathrm{m}^{2}$; DE: mean $=5.1 \times 10^{4} \mu \mathrm{m}^{2}, \mathrm{std}^{2}=2.5 \times 10^{4} \mu \mathrm{m}^{2}$ ), $0.82\left(\mathrm{NR}:\right.$ mean $=2.8 \times 10^{4} \mu \mathrm{m}^{2}$, std $=1.5 \times 10^{4} \mu \mathrm{m}^{2}$; DE: mean $=2.7 \times 10^{4} \mu \mathrm{m}^{2}$, std $\left.=1.7 \times 10^{4} \mu \mathrm{m}^{2}\right)$, and $0.14(\mathrm{NR}:$ mean $=3.5 \times 10^{4} \mu \mathrm{m}^{2}$, std $=1.8 \times 10^{4} \mu \mathrm{m}^{2}$; DE: mean $=2.6 \times 10^{4} \mu \mathrm{m}^{2}$, std $\left.=2.41 \times 10^{4} \mu \mathrm{m}^{2}\right)$, respectively. $\boldsymbol{D}$, Distributions of the distance of $80 \%$ of input to each L4 cell originating from L2/3 (top), L4 (middle), and L5/6 (bottom) of NR (red) or DE (black) animals. $*, p<0.05$. All comparisons were done with Wilcoxon rank-sum test or Student's $t$ test. The $p$ values for the average $80 \%$ distance from L2/3, L4, and L5/6 are 0.34 (NR: mean $=190.4 \mu \mathrm{m}$, std $=42.7 \mu \mathrm{m}$; DE: mean $=204.0 \mu \mathrm{m}$, std $=56.2 \mu \mathrm{m}$ ), 0.95 (NR: mean $=209.3 \mu \mathrm{m}$, std $=41.0 \mu \mathrm{m}$; DE: mean $=208.4 \mu \mathrm{m}$, std $=56.2 \mu \mathrm{m})$, and $0.74(\mathrm{NR}:$ mean $=237.9 \mu \mathrm{m}$, std $=$ $74.7 \mu \mathrm{m}$; DE: mean $=228.6 \mu \mathrm{m}$, std $=108.8 \mu \mathrm{m})$, respectively.

changes in connections of neurons that are very close to the patched cell, and it is possible that DE strongly affects these very local connections.

As in our prior studies (Goel et al., 2006; He et al., 2012; Petrus et al., 2014; Meng et al., 2015), we here performed our visual deprivation on animals within the critical period for V1 plasticity but after the critical period for A1 plasticity (Barkat et al., 2011; Espinosa and Stryker, 2012). Because we have shown that crossmodal synaptic plasticity occurs in adults (Petrus et al., 2014, 2015), the changes 
A
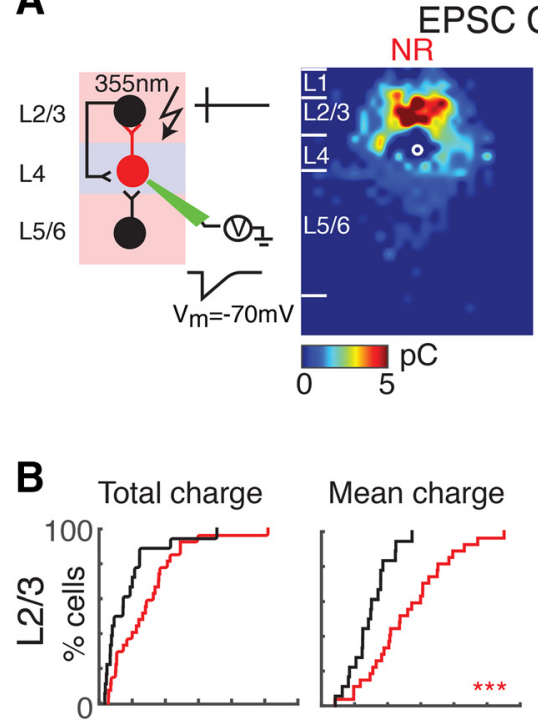

Mean charge
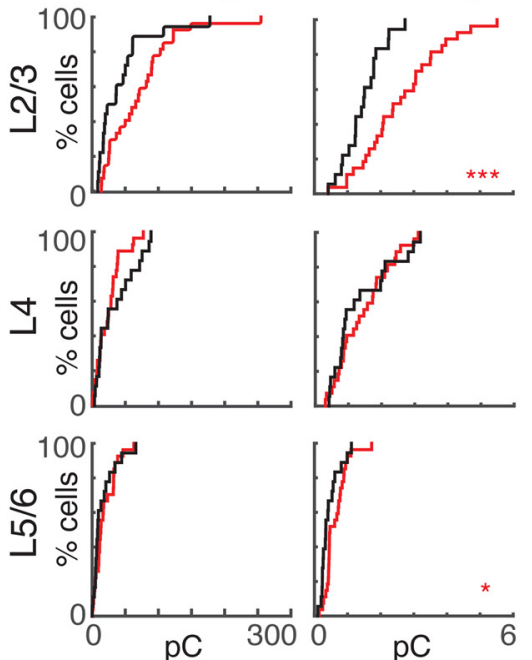
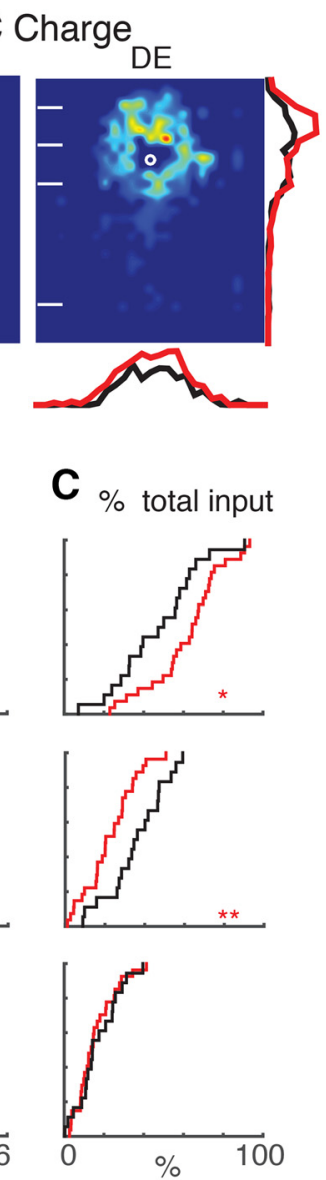

D
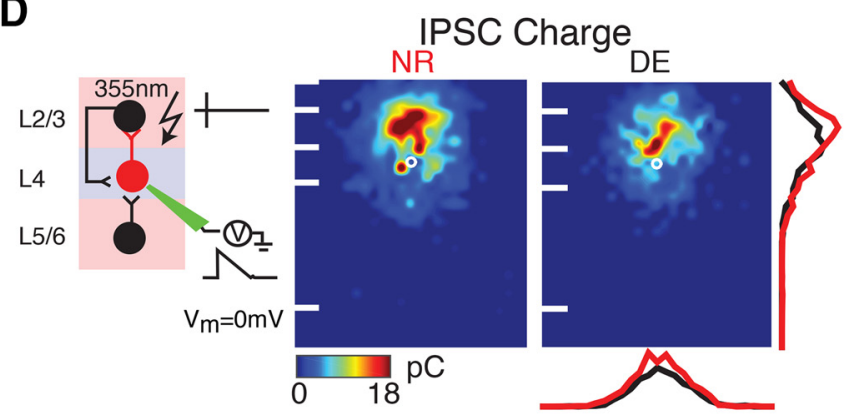

$\mathbf{E}$

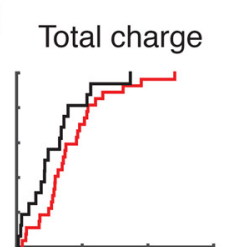

Mean charge
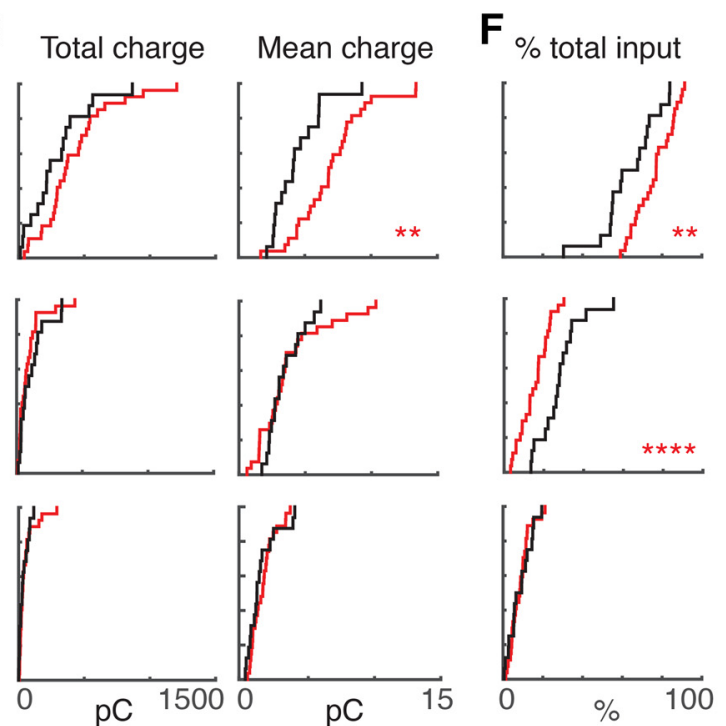

Figure 4. The EPSC and IPSC charge of interlaminar cortical connections to L4 cells decreases. A, Average maps (aligned to soma, white circle) of connection strength (transferred charge) for excitatory inputs in NR (left) and DE (right) animals. Averages are calculated only for stimulation sites that evoked responses in $>10 \%$ of cells in our sample. Connection strength is encoded according to the pseudocolor scale. White horizontal lines indicate averaged laminar borders and are $100 \mu \mathrm{m}$ long. Traces at the right of DE panel are the laminar marginal distributions (red for NR and black for DE). Traces at the bottom of the DE panel are the columnar marginal distributions. Note that NR and DE maps and distributions appear different. $\boldsymbol{B}$, Distributions of total (left) and mean EPSC (right) input charge originating from L2/3 (top), L4 (middle), and L5/6 (bottom) of NR (red) or DE (black) animals. *, $p<0.05 ; * * *, p$ $<0.01$. The $p$ values for the total charge from L2/3, L4, and L5/6 are 0.06 (NR: mean $=71 \mathrm{pC}$, std $=52.6 \mathrm{pC}$; DE: mean $=42.6 \mathrm{pC}$, std $=42.4 \mathrm{pC}$ ), 0.17 (NR: mean $=25 \mathrm{pC}$, std = $19.5 \mathrm{pC}$; DE: mean $=35.2 \mathrm{pC}$, std = $29.7 \mathrm{pC}$ ), and 0.37 (NR: mean $=18.5 \mathrm{pC}$, std $=15.6 \mathrm{pC}$; DE: mean $=15.8 \mathrm{pC}$, std $=17.3 \mathrm{pC})$, respectively. The $p$ values for the mean EPSC charge from L23, L4, and L5/6 are $8.1 \times 10^{-4}(\mathrm{NR}:$ mean $=2.59 \mathrm{pC}$, std $=1.23 \mathrm{pC}$; DE: mean $=1.46 \mathrm{pC}$, std =0.6 pC), 0.73 (NR: mean $=1.45 \mathrm{pC}$, std $=0.8 \mathrm{pC}$; DE: mean $=1.36 \mathrm{pC}$, std $=0.91 \mathrm{pC}$ ), and 0.02 (NR: mean $=0.63 \mathrm{pC}$, std $=0.33 \mathrm{pC}$; DE: mean $=0.45 \mathrm{pC}$, std $=0.28 \mathrm{pC}$ ), respectively. All comparisons were done with Wilcoxon rank-sum test or Student's $t$ test. $\boldsymbol{C}$, Distributions of fractional EPSC charge originating from L2/3 (top), L4 (middle), and L5/6 (bottom) for cells from NR (red) or DE (black) animals. L2/3: $p=0.015$ (NR: mean = 0.62 , std = 0.18 ; $\mathrm{DE}:$ mean $=0.47$, std $=0.21)$, L4: $p=0.002(\mathrm{NR}$ : mean $=0.22$, std $=0.13$; DE: mean $=0.37$, std $=0.15)$, and L5/6: $p=0.67(\mathrm{NR}$ : mean $=0.16$, std $=0.1$; DE: mean $=0.17$, std $=0.11$ ). $\boldsymbol{D}$. Average maps (aligned to soma, white circle) of connection strength (transferred charge) for inhibitory inputs in NR (left) and DE (right) animals. Averages are calculated only for stimulation sites that evoked responses in $>10 \%$ of cells in our sample. Note that NR and DE maps and distributions appear different. $\boldsymbol{E}$, Distributions of total (left) and mean (right) IPSC input charge originating from L2/3 (top), L4 (middle), and L5/6 (bottom) of NR (red) or DE (black) animals. $*, p<0.05$; $* * *, p<0.01$. The $p$ values of the total IPSC charge from L2/3, L4, and L5/6 are 0.11 (NR: mean $=413.8$ pC, std $=265.7 \mathrm{pC}$; DE: mean $=285.2 \mathrm{pC}$, std $=227.7 \mathrm{pC}), 0.37$ (NR: mean $=87.4 \mathrm{pC}$, std $=94.3 \mathrm{pC} ; \mathrm{DE}:$ mean $=115.3 \mathrm{pC}$, std $=$ $104 \mathrm{pC}$ ), and 0.41 (NR: mean $=51.4 \mathrm{pC}$, std $=63.7 \mathrm{pC}$; DE: mean $=37.2 \mathrm{pC}$, std $=35.1 \mathrm{pC}$ ), respectively. The $p$ values of the mean IPSC charge from L23, L4, and L5/6 are $1.2 \times 10^{-3}$ (NR: mean $=7.01 \mathrm{pC}$, std = $2.69 \mathrm{pC}$; DE: mean $=4.35 \mathrm{pC}$, std $\left.=1.87 \mathrm{pC}\right), 0.67$ (NR: mean $=3.71 \mathrm{pC}$, std $=2.53 \mathrm{pC}$; DE: mean $=3.42 \mathrm{pC}$, std $=1.33 \mathrm{pC}$ ), and 0.67 (NR: mean $=1.58 \mathrm{pC}$, std $=0.88 \mathrm{pC}$; DE: mean $=1.44 \mathrm{pC}$, std $=01.13 \mathrm{pC}$ ), respectively. All comparisons were done with Wilcoxon rank-sum test or Student's $t$ test. $\boldsymbol{F}$, Distributions of fractional IPSC charge originating from L2/3 (top), L4 (middle), and L5/6 (bottom) for cells from NR (red) or DE (black) animals: $p$ $=0.001$ (NR: mean $=0.76$, std $=0.1$; DE: mean $=0.64$, std $=0.14)$, L4: $p=4.12 * 10^{-5}(\mathrm{NR}:$ mean $=0.15$, std $=0.07 ; \mathrm{DE}:$ mean $=0.28$, std $=0.11$, and L5/6: $p=0.961$ (NR: mean $=0.08$, std $=0.05$; DE: mean $=0.09$, std $=0.06$ ). 
A

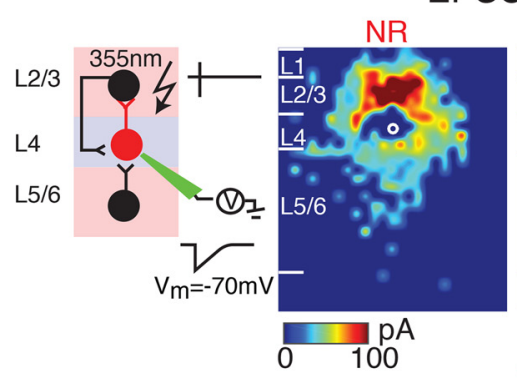

B
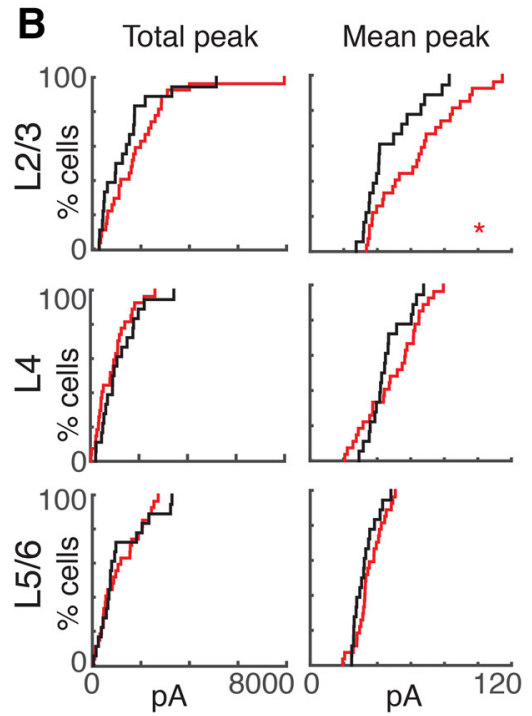

EPSC Peak

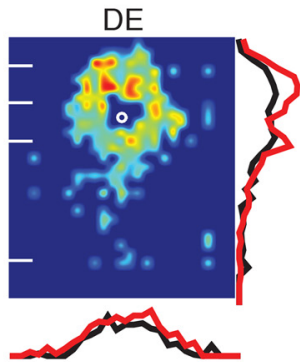

C \% total input
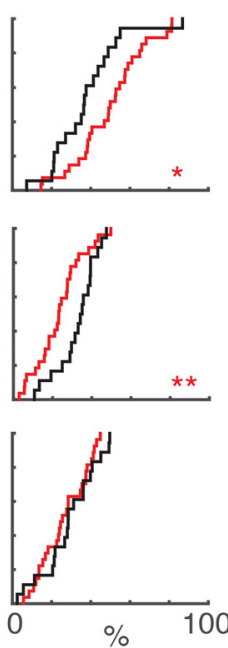

D

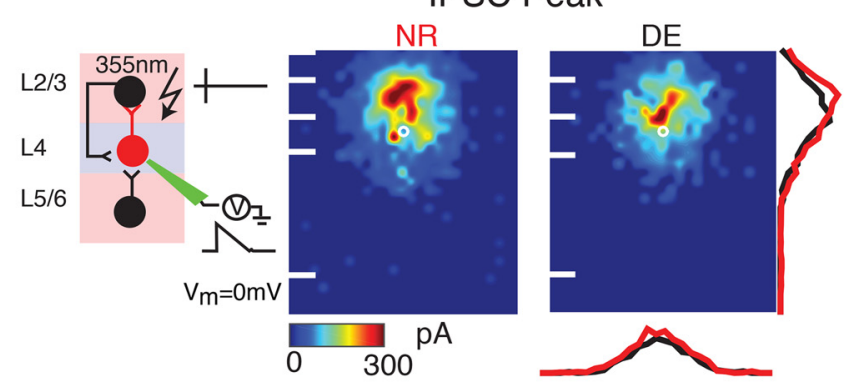

E

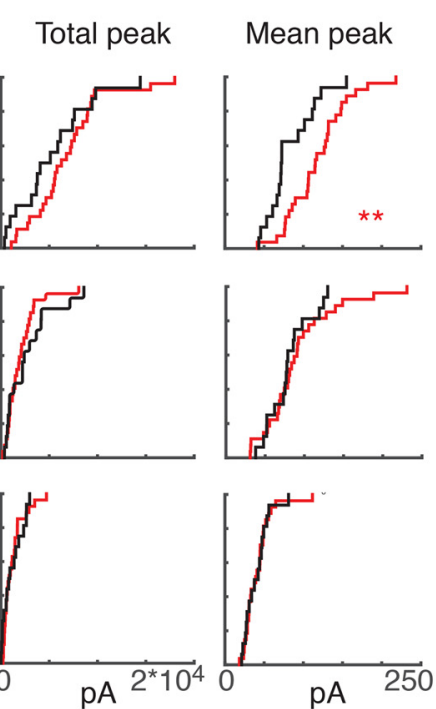

F
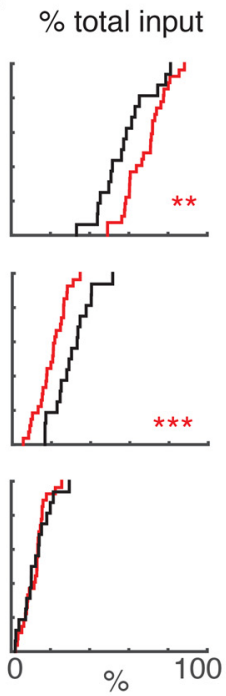

Figure 5. The EPSC and IPSC peak amplitude of interlaminar cortical connections to L4 cells decreases. A, Average maps (aligned to soma, white circle) of peak amplitude for excitatory inputs in NR (left) and DE (right) animals. Averages are calculated only for stimulation sites that evoked responses in $>10 \%$ of cells in our sample. Peak amplitude is encoded according to the pseudocolor scale. White horizontal lines indicate averaged laminar borders and are $100 \mu \mathrm{m}$ long. Traces at the right of the DE panel are the laminar marginal distributions (red for NR and black for DE). Traces at the bottom of the DE panel are the columnar marginal distributions. Note that NR and DE maps and distributions appear different. $\boldsymbol{B}$, Distributions of total (left) and mean (right) EPSC peak amplitude originating from L2/3 (top), L4 (middle), and L5/6 (bottom) of NR (red) or DE (black) animals. $*, p<0.05 ; * *, p<0.01$. The $p$ values for the total peak from L2/3, L4, and L5/6 are 0.25 (NR: mean $=1.89 \times 10^{3} \mathrm{pA}$, std $=1.55 \times 10^{3} \mathrm{pA}$; DE: mean $=1.38 \times 10^{3} \mathrm{pA}$, std $\left.=1.22 \times 10^{3} \mathrm{pA}\right), 0.24\left(\mathrm{NR}:\right.$ mean $=9.05 \times 10^{2} \mathrm{pA}$, std $=6.81 \times 10^{2} \mathrm{pA}$; DE: mean $=1.17 \times 10^{3} \mathrm{pA}$, std $\left.=8.23 \times 10^{2} \mathrm{pA}\right)$, and $0.99\left(\mathrm{NR}\right.$ : mean $=1.11 \times 10^{3} \mathrm{pA}$, std $=8.39 \times 10^{2} \mathrm{pA}$; DE: mean $=1.11 \times 10^{3} \mathrm{pA}$, std $\left.=9.98 \times 10^{2} \mathrm{pA}\right)$, respectively. The $p$ values for the mean peak from L2/3, L4, and L5/6 are 0.02 (NR: mean $=63.4 \mathrm{pA}$, std $=24.3 \mathrm{pA} ; \mathrm{DE}$ : mean $=47.4 \mathrm{pA}$, std $=16.9$ $\mathrm{pA}), 0.42(\mathrm{NR}$ : mean $=49.4 \mathrm{pA}$, std = $16.8 \mathrm{pA}$; DE: mean $=45.7 \mathrm{pA}$, std = $11.1 \mathrm{pA})$, and $0.2(\mathrm{NR}$ : mean $=35.4 \mathrm{pA}$, std = $8.15 \mathrm{pA}$; $\mathrm{DE}$ : mean $=32.3 \mathrm{pA}$, std $=6.85 \mathrm{pA}$ ), respectively. All comparisons were done with Wilcoxon rank-sum test or Student's $t$ test. $\mathbf{C}$, Distributions of fractional EPSC amplitude originating from L2/3 (top), L4 (middle), and L5/6 (bottom) for cells from NR (red) or DE (black) animals. L2/3: $p=0.03$ (NR: mean $=0.50$, std $=0.18$; DE: mean $=0.37$, std $=0.18)$, L4: $p=0.009$ (NR: mean $=0.23$, std $=0.12$; DE: mean $=0.33$, std =0.10), and L5/6: $p=0.5(\mathrm{NR}$ : mean $=0.26$, std =0.12; DE: mean $=0.29$, std $=0.14)$. $\boldsymbol{D}$, Average maps (aligned to soma, white circle) of connection strength (transferred peak) for inhibitory inputs in NR (left) and DE (right) animals. Averages are calculated only for stimulation sites that evoked responses in $>10 \%$ of cells in our sample. Traces at the right of the DE panel are the laminar marginal distributions (red for NR and black for DE). Traces at the bottom of the DE panel are the columnar marginal distributions. Note that NR and DE maps and distributions appear different. $E$, Distributions of total (left) and mean (right) IPSC peak amplitude originating from L2/3 (top), L4 (middle), and L5/6 (bottom) of NR (red) or DE (black) animals. *, $p<0.05$; $* * *$, $p<0.01$. The $p$ values for the total peak from L23, L4, and L5/6 are 0.22 (NR: mean $=6.74 \times 10^{3} \mathrm{pA}$, std $=3.83 \times 10^{3} \mathrm{pA}$; DE: mean $=5.24 \times 10^{3} \mathrm{pA}$, std $\left.=3.85 \times 10^{3} \mathrm{pA}\right), 0.28\left(\mathrm{NR}\right.$ : mean $=2.01 \times 10^{3} \mathrm{pA}$, std $=1.63 \times 10^{3} \mathrm{pA} ; \mathrm{DE}: \mathrm{mean}=2.69 \times 10^{3} \mathrm{pA}$, std $=$ $\left.2.40 \times 10^{3} \mathrm{pA}\right)$, and $0.91\left(\mathrm{NR}:\right.$ mean $=1.23 \times 10^{3} \mathrm{pA}$, std $=1.10 \times 10^{3} \mathrm{pA}$; DE: mean $\left.=1.19 \times 10^{3} \mathrm{pA}, \mathrm{std}=1.02 \times 10^{3} \mathrm{pA}\right)$, respectively. The $p$ values for the mean peak from L23, L4, and L5/6 are 0.004 (NR: mean $=118$ pA, std = 38.4 pA; DE: mean $=82.8$ $\mathrm{pA}$, std = 30.9 pA), 0.42 (NR: mean = 90.1 pA, std = 46.0 pA; DE: mean = 79.8 pA, std = $27.3 \mathrm{pA})$, and $0.86(\mathrm{NR}$ : $\mathrm{mean}=41.5 \mathrm{pA}$, std $=18.3 \mathrm{pA} ; \mathrm{DE}$ : mean $=40.5 \mathrm{pA}$, std $=15.5 \mathrm{pA})$, respectively. All comparisons were done with Wilcoxon rank-sum test or Student's $t$ test. $\boldsymbol{F}$, Distributions of fractional IPSC amplitude originating from L2/3 (top), L4 (middle), and L5/6 (bottom) for cells from $\mathrm{NR}$ (red) or DE (black) animals. L2/3: $p=4.7 \times 10^{-3}(\mathrm{NR}$ : mean $=0.68$, std $=0.10 ; \mathrm{DE}:$ mean $=0.57$, std $=0.13), \mathrm{L} 4: p=2.95 \times$ $10^{-4}$ (NR: mean $=0.20$, std $=0.07$; DE: mean $=0.30$, std =0.09), and L5/6: $p=0.83($ NR: mean $=0.12$, std $=0.06$; DE: mean $=$ 0.12 , std $=0.07$ ). All comparisons were done with Wilcoxon rank-sum test or Student's $t$ test. 


\section{E:I area}
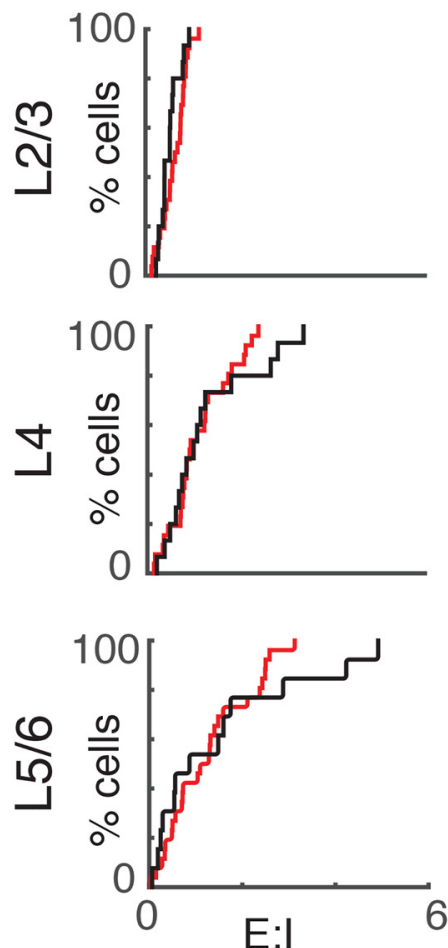

E:I charge
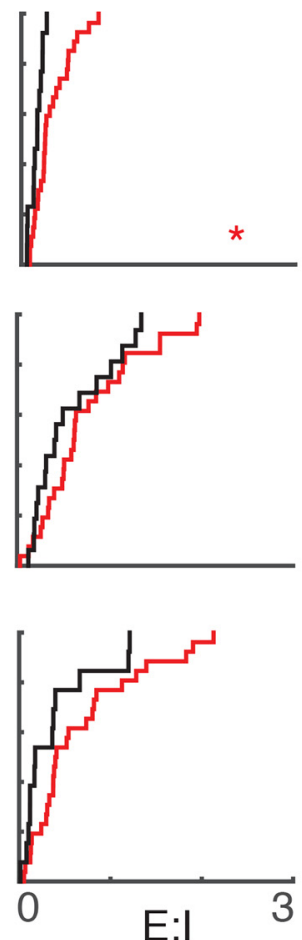

E:I peak
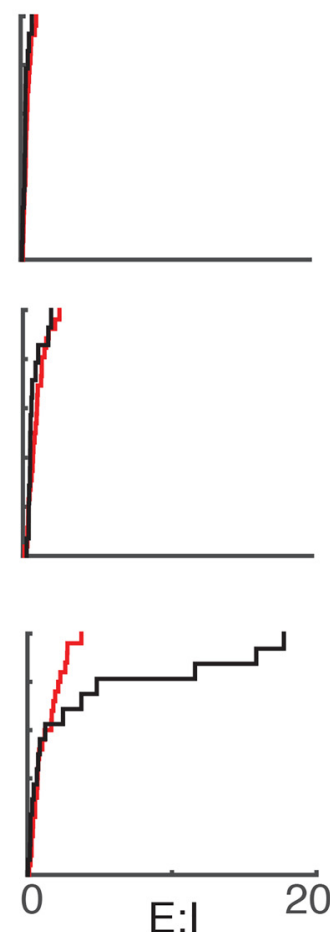

Figure 6. The balance of excitation and inhibition of L2/3 inputs to L4 is reduced. Cumulative distributions (CDFs) of excitation/ inhibition (El) area ratio (left), charge ratio (middle), and peak amplitude ratio (right) from L2/3 (top), L4 (middle), and L5/6 (bottom) in $\mathrm{NR}$ and DE cells. The charge ratio of L2/3 inputs decreased after DE (El area ratio: L2/3: $p=0.2, \mathrm{~L} 4: p=0.53$, L5/6: $p=0.55 ; \mathrm{EI}$ charge ratio: L2/3: $p=0.007, \mathrm{~L} 4: p=0.26$, L5/6: $p=0.08$; El amplitude ratio: L2/3: $p=0.12, \mathrm{~L} 4: p=0.29$, L5/6: $p=0.90$ ). All comparisons were done with Wilcoxon rank-sum test or Student's $t$ test.

observed here are not likely restricted to the visual deprivation within the V1 critical period.

Our results suggest that the changes after DE include spatial refinement of intracortical inputs to $A 1 L 4$ neurons into fewer synapses while thalamocortical synapses strengthen. Thus, the combined effect of these balanced circuit changes will be enhanced transmission of ascending auditory information. The relative increase in feedforward connectivity by DE may lead to enhancement of spectro-temporal responses in A1 observed in our previous study (Petrus et al., 2014).

Visual deprivation causes pronounced changes in the functional circuits of both L4 and L2/3 in A1. Despite these profound effects, it is unclear how these changes come about. The functional responses in A1 can be modulated by behavior and attention, and these changes are mediated by modulatory and top-down pathways (Kilgard and Merzenich, 1998; Bao et al., 2001; Fritz et al., 2003, 2007; Winkowski et al., 2013, 2017). Because animals in the dark likely pay more attention, an enhanced engagement of these plasticity processes could lead to the observed circuit changes. A nonexclusive further possibility is that the observed changes reflect homeostatic adjustment of latent multisensory processing in $A 1$. Because extrastriate visual cortex can alter A1 activity (Banks et al., 2011), decreased visual activity during DE could lead to a homeostatic rebalancing of auditory circuits. Although our experiments cannot distinguish between these mechanisms, the sum of our observations indicates changes in both excitatory and inhibitory connections consequent to $D E$ in $L 4$ as well as $L 2 / 3$. Our results thus reveal a powerful effect of cross-modal inputs on the intrinsic circuitry across the different layers of $\mathrm{A} 1$.

\section{References}

Bandyopadhyay S, Shamma SA, Kanold PO (2010) Dichotomy of functional organization in the mouse auditory cortex. Nat Neurosci 13:361-368. CrossRef

Banks MI, Uhlrich DJ, Smith PH, Krause BM, Manning KA (2011) Descending projections from extrastriate visual cortex modulate responses of cells in primary auditory cortex. Cereb Cortex 21: 2620-2638. CrossRef Medline

Bao S, Chan VT, Merzenich MM (2001) Cortical remodelling induced by activity of ventral tegmental dopamine neurons. Nature 412: 79-83. CrossRef Medline

Barbour DL, Callaway EM (2008) Excitatory local connections of superficial neurons in rat auditory cortex. J Neurosci 28:1117411185. CrossRef Medline

Barkat TR, Polley DB, Hensch TK (2011) A critical period for auditory thalamocortical connectivity. Nat Neurosci 14:1189-1194. CrossRef Medline

Bavelier D, Neville HJ (2002) Cross-modal plasticity: where and how? Nat Rev Neurosci 3:443-452. CrossRef Medline

Cruikshank SJ, Rose HJ, Metherate R (2002) Auditory thalamocortical synaptic transmission in vitro. J Neurophysiol 87:361-384. Medline 
Espinosa JS, Stryker MP (2012) Development and plasticity of the primary visual cortex. Neuron 75:230-249. CrossRef Medline

Fritz J, Shamma S, Elhilali M, Klein D (2003) Rapid task-related plasticity of spectrotemporal receptive fields in primary auditory cortex. Nat Neurosci 6:1216-1223. CrossRef Medline

Fritz JB, Elhilali M, David SV, Shamma SA (2007) Auditory attentionfocusing the searchlight on sound. Curr Opin Neurobiol 17:437455. CrossRef Medline

Ghazanfar AA, Schroeder CE (2006) Is neocortex essentially multisensory? Trends Cogn Sci 10:278-285. CrossRef Medline

Goel A, Jiang B, Xu LW, Song L, Kirkwood A, Lee HK (2006) Cross-modal regulation of synaptic AMPA receptors in primary sensory cortices by visual experience. Nat Neurosci 9:1001-1003. CrossRef Medline

Gougoux F, Lepore F, Lassonde M, Voss P, Zatorre RJ, Belin P (2004) Neuropsychology: pitch discrimination in the early blind. Nature 430:309. CrossRef Medline

He K, Petrus E, Gammon N, Lee HK (2012) Distinct sensory requirements for unimodal and cross-modal homeostatic synaptic plasticity. J Neurosci 32:8469-8474. CrossRef Medline

Ibrahim LA, Mesik L, Ji XY, Fang Q, Li HF, Li YT, Zingg B, Zhang LI, Tao HW (2016) Cross-modality sharpening of visual cortical processing through layer-1-mediated inhibition and disinhibition. Neuron 89:1031-1045. CrossRef Medline

Iurilli G, Ghezzi D, Olcese U, Lassi G, Nazzaro C, Tonini R, Tucci V, Benfenati F, Medini P (2012) Sound-driven synaptic inhibition in primary visual cortex. Neuron 73:814-828. CrossRef Medline

Kanold PO, Nelken I, Polley DB (2014) Local versus global scales of organization in auditory cortex. Trends Neurosci 37:502-510. CrossRef

Kao JPY (2006) Caged molecules: principles and practical considerations. In: Current Protocols in Neuroscience (Gerfen C, Holmes A, Rogawski M, Sibley D, Skolnick P, Wray S, eds). Hoboken, NJ: Wiley.

Kilgard MP, Merzenich MM (1998) Cortical map reorganization enabled by nucleus basalis activity. Science 279:1714-1718. Medline

Kratz MB, Manis PB (2015) Spatial organization of excitatory synaptic inputs to layer 4 neurons in mouse primary auditory cortex. Front Neural Circ 9:17. CrossRef Medline

Lakatos P, Chen CM, O'Connell MN, Mills A, Schroeder CE (2007) Neuronal oscillations and multisensory interaction in primary auditory cortex. Neuron 53:279-292. CrossRef Medline

Lee HK, Whitt JL (2015) Cross-modal synaptic plasticity in adult primary sensory cortices. Curr Opin Neurobiol 35:119-126. CrossRef Medline

Lessard N, Paré M, Lepore F, Lassonde M (1998) Early-blind human subjects localize sound sources better than sighted subjects. Nature 395:278-280. CrossRef Medline

Li LY, Li YT, Zhou M, Tao HW, Zhang LI (2013) Intracortical multiplication of thalamocortical signals in mouse auditory cortex. Nat Neurosci 16:1179-1181. CrossRef Medline

Li LY, Ji XY, Liang F, Li YT, Xiao Z, Tao HW, Zhang LI (2014) A feedforward inhibitory circuit mediates lateral refinement of sen- sory representation in upper layer $2 / 3$ of mouse primary auditory cortex. J Neurosci 34:13670-13683. CrossRef Medline

Meng X, Kao JP, Kanold PO (2014) Differential signaling to subplate neurons by spatially specific silent synapses in developing auditory cortex. J Neurosci 34:8855-8864. CrossRef Medline

Meng X, Kao JP, Lee HK, Kanold PO (2015) Visual deprivation causes refinement of intracortical circuits in the auditory cortex. Cell Rep 12:955-964. CrossRef Medline

Muralidharan S, Dirda ND, Katz EJ, Tang CM, Bandyopadhyay S, Kanold PO, Kao JP (2016) Ncm, a photolabile group for preparation of caged molecules: synthesis and biological application. PLoS One 11:e0163937. CrossRef Medline

Petrus E, Rodriguez G, Patterson R, Connor B, Kanold PO, Lee HK (2015) Vision loss shifts the balance of feedforward and intracortical circuits in opposite directions in mouse primary auditory and visual cortices. J Neurosci 35:8790-8801. CrossRef Medline

Petrus E, Isaiah A, Jones AP, Li D, Wang H, Lee HK, Kanold PO (2014) Crossmodal induction of thalamocortical potentiation leads to enhanced information processing in the auditory cortex. Neuron 81:664-673. CrossRef Medline

Röder B, Teder-Sälejärvi W, Sterr A, Rösler F, Hillyard SA, Neville HJ (1999) Improved auditory spatial tuning in blind humans. Nature 400:162-165. CrossRef Medline

Schroeder CE, Foxe J (2005) Multisensory contributions to low-level, 'unisensory' processing. Curr Opin Neurobiol 15:454-458. CrossRef Medline

Shepherd GM, Pologruto TA, Svoboda K (2003) Circuit analysis of experience-dependent plasticity in the developing rat barrel cortex. Neuron 38:277-289. Medline

Suter BA, O'Connor T, lyer V, Petreanu LT, Hooks BM, Kiritani T, Svoboda K, Shepherd GM (2010) Ephus: multipurpose data acquisition software for neuroscience experiments. Front Neural Circ 4:100. CrossRef Medline

Viswanathan S, Bandyopadhyay S, Kao JP, Kanold PO (2012) Changing microcircuits in the subplate of the developing cortex. $J$ Neurosci 32:1589-1601. CrossRef Medline

Watkins PV, Kao JP, Kanold PO (2014) Spatial pattern of intralaminar connectivity in supragranular mouse auditory cortex. Front Neural Circ 8:15. CrossRef Medline

Winkowski DE, Kanold PO (2013) Laminar transformation of frequency organization in auditory cortex. J Neurosci 33:1498-1508. CrossRef Medline

Winkowski DE, Bandyopadhyay S, Shamma SA, Kanold PO (2013) Frontal cortex activation causes rapid plasticity of auditory cortical processing. J Neurosci 33:18134-18148. CrossRef Medline

Winkowski DE, Nagode DA, Donaldson KJ, Yin P, Shamma SA, Fritz JB, Kanold PO (2017) Orbitofrontal cortex neurons respond to sound and activate primary auditory cortex neurons. Cereb Cortex CrossRef

Zhao C, Kao JP, Kanold PO (2009) Functional excitatory microcircuits in neonatal cortex connect thalamus and layer 4. J Neurosci 29:15479-15488. CrossRef Medline 